\title{
Novel psychoactive substance use by US adolescents: Characteristics associated with use of synthetic cannabinoids and synthetic cathinones
}

\author{
MEGAN E. PATRICK ${ }^{1}$, PATRICK M. O'MALLEY ${ }^{1}$, DEBORAH D. KLOSKA ${ }^{1}$, \\ JOHN E. SCHULENBERG ${ }^{1,2}$, LLOYD D. JOHNSTON ${ }^{1}$, RICHARD A. MIECH ${ }^{1}$ \& \\ JERALD G. BACHMAN ${ }^{1}$
}

${ }^{1}$ Institute for Social Research, University of Michigan, Ann Arbor, USA, and ${ }^{2}$ Department of Psychology, University of Michigan, Ann Arbor, USA

\begin{abstract}
Introduction and Aims. The current study documents the characteristics associated with the use of two novel psychoactive substances: synthetic cannabinoids and synthetic cathinones. Design and Methods. Nationally representative samples of students in 8th $(n=9665), 10$ th $(n=10655)$ and 12th $(n=10057)$ grades across the US were included in the Monitoring the Future study from 2012 to 2014. Results. There were relatively few differences in prevalence based on sociodemographic characteristics, although boys were at greater risk for use of synthetic cannabinoids in 12th grade (used by 10.3\% of boys and $6.4 \%$ of girls) and for use of synthetic cathinones in 10th grade (used by $1.0 \%$ of boys and $0.4 \%$ of girls). Synthetic drug use was also associated with truancy and use of cigarettes, alcohol, and marijuana. Discussion and Conclusions. Prevention and intervention efforts for novel psychoactive substance use should focus primarily on polysubstance users and youth who are disengaged from school. [Patrick M, O’Malley P, Kloska D, Schulenberg J, Johnston L, Miech R, Bachman J. Novel psychoactive substance use by US adolescents: Characteristics associated with use of synthetic cannabinoids and synthetic cathinones. Drug Alcohol Rev 2016;35:586-590]
\end{abstract}

Key words: synthetic cannabinoids, synthetic cathinones, synthetic marijuana, bath salts, novel psychoactive substances.

\section{Introduction}

Synthetic drugs are 'barely legal toxic highs' [1], substances with 'psychotropic effects that are intentionally marketed and distributed for recreational use by exploiting inadequacies of existing controlled substance legislation' [2]. These novel psychoactive substances are often labeled 'not for human consumption' (to avoid legal culpability in the US) but are used to get high [2]. Testimony by the Director of the US National Institute on Drug Abuse has highlighted the public health issues related to these substances [3]. In April 2015, the American Association of Poison Control Centers [4] issued a warning about the emergence of new synthetic drug compounds, as the chemical properties of the drugs continue to change. Synthetic drugs are very difficult to regulate because of the rapidly changing and widely varying chemical compounds; when regulation is enforced for a specific version of the drug, new variants often emerge (see [5] for a review of legal status in the US).

Synthetic cannabinoids (also called synthetic marijuana or spice) refer to a combination of herbs and manufactured chemicals that mimic cannabinoids found in marijuana but can have much stronger effects [6-9]. Among adolescents in the US synthetic cannabinoids are the most-used illicit drug after marijuana $[2,10,11]$. Little is known about the health consequences of their use [3] although associated physical effects include seizures, chest pain, vomiting and breathing problems [12-14] and psychoactive effects include panic, anxiety, paranoia and psychosis [14-16], as well as possible drug dependence [12].

Synthetic cathinones, typically called bath salts, are stimulants very similar to amphetamines such as methamphetamine and MDMA [6-8]. Synthetic cathinones can be powerful drugs [3] that can lead to acute physical and neuropsychiatric symptoms including seizure, heart

Megan E. Patrick, PhD, Research Assistant Professor, Patrick M. O’Malley, PhD, Research Professor, Deborah D. Kloska, MA, Research Associate, John E. Schulenberg, PhD, Research Professor, Lloyd D. Johnston, PhD, Research Professor, Richard A. Miech, PhD, Research Professor, Jerald G. Bachman, PhD, Research Professor. Correspondence to Dr Megan E. Patrick, Ph.D., Institute for Social Research, University of Michigan, 426 Thompson Street, Ann Arbor, MI 48106-1248, USA. Tel: 734-763-7107; Fax: 734-936-0043; E-mail: meganpat@umich.edu

Received 10 July 2015; accepted for publication 19 November 2015. 
attack and psychosis [17], as well as addiction [18]. These drugs have been linked to high numbers of emergency department visits [19].

Despite the dangers associated with synthetic drug use, little is known about characteristics associated with use among adolescents [11]. The present analysis was designed to examine the prevalence of synthetic cannabinoids and synthetic cathinones as well as the sociodemographic and adolescent school and social engagement characteristics associated with their use among 8th-, 10th- and 12th-grade students in the US.

\section{Methods}

\section{Participants and procedures}

Monitoring the Future data derive from annual, national samples of 8th-, 10th- and 12th-grade students in the US. This study analysed data of US 8th $(n=9665)$, 10th $(n=10655)$ and 12th graders $(n=10057)$ from 2012 through 2014 (see $[10,20]$ for study design).

\section{Measures}

School-based surveys from 2012 to 2014 included questions about students' use of synthetic cannabinoids, described as " "synthetic marijuana" ("K2," "Spice") to get high,' and synthetic cathinones, described as 'bath salts (synthetic stimulants) to get high,' in the past 12 months. Sociodemographics (geographical region of country, population density, gender, race/ethnicity, parent education, and two-parent family structure), adolescent engagement (school grades, truancy [i.e. cutting class], number of evenings out for fun and recreation), and other substances use (cigarettes in the past 30 days, alcohol and marijuana in the past 12 months) were also included.

\section{Statistical analysis}

All analyses used SAS software [21] survey procedures to account for the complex sample design [10]. Prevalence of 'synthetic marijuana' and 'bath salts' use by grade and covariates was computed using weighted means. Logistic regression was used for pairwise comparisons of covariates with use and for the multivariable models predicting use.

\section{Results}

'Synthetic marijuana' use in the past 12 months was reported by $3.5 \%$ of US 8 th graders, $7.2 \%$ of 10 th graders and $8.3 \%$ of 12 th graders for the years $2012-2014$ combined. 'Bath salts' use in the past 12 months was reported by $0.6 \%$ of 8 th graders, $0.7 \%$ of 10 th graders and $0.7 \%$ of 12th graders. Table 1 shows use by cohort year and sociodemographic subgroups. Pairwise comparisons within grades are shown for each set of variables. 'Synthetic marijuana' use declined significantly from 2012 to 2014 among 10th and 12th graders but not 8th graders; 'bath salts' use did not change significantly. Gender differences emerged for 12th graders' use of 'synthetic marijuana' $(10.3 \%$ of boys, $6.4 \%$ of girls) and for 10th graders' use of 'bath salts' ( $1.0 \%$ of boys, $0.4 \%$ of girls). Use was consistently lower among adolescents living with two parents. Among students who have used 'synthetic marijuana,' $11.6 \%$ of 8 th graders, $6.7 \%$ of 10 th graders and $6.3 \%$ of 12 th graders also used 'bath salts.'

\section{Synthetic cannabinoid use}

In multivariable comparisons in logistic regression models (Table 2), recent cohorts had progressively significantly lower prevalence of 'synthetic marijuana' use among 10th and 12th graders, but not among eighth graders. With only one exception, region was not a significant predictor in these models. There were no significant differences based on population density or gender, with the exception that, among 12th graders, boys had higher odds of using 'synthetic marijuana' than girls did. Hispanic eighth graders had higher odds of using than White eighth graders, and Black 10th graders had lower odds of using than White 10th graders; otherwise, race/ethnicity did not emerge as a consistent predictor in the multivariable model. Parent college education among 10th graders was associated with lower odds of using 'synthetic marijuana', but family structure was not significant. Adolescent school and social engagement factors were also associated with use. Having higher grades in school was associated with less use for eighth graders. Truancy, number of evenings out for fun and recreation per week, cigarette use in the past 30 days and alcohol and marijuana use in the past 12 months were all associated with 'synthetic marijuana' use.

\section{Synthetic cathinones use}

In multivariable models (Table 2), 10th graders had higher odds of using 'bath salts' in 2014 than in 2012 (reference year). Sociodemographic factors were not predictive of use, with the exception that 10th-grade boys had higher odds of use than 10th-grade girls and that Black youth in 12th grade had higher odds of use than White youth. Adolescent engagement factors were associated with 'bath salts' use. Having higher grades in school was associated with less use among eighth graders. Truancy for 8 th and 10 th graders, cigarette use in the past 30 days, alcohol use in the past 12 months for 10th graders and 
Table 1. Prevalence of use of synthetic cannabinoids and synthetic cathinones in the past 12 months by grade and covariates

\begin{tabular}{|c|c|c|c|c|c|c|}
\hline & \multicolumn{3}{|c|}{ 'Synthetic marijuana' use } & \multicolumn{3}{|c|}{ 'Bath salts' use } \\
\hline & 8th grade & 10th grade & 12th grade & 8th grade & 10th grade & 12 th grade \\
\hline \multicolumn{7}{|l|}{ By subgroup } \\
\hline \multicolumn{7}{|l|}{ Cohort year } \\
\hline 2012 & $3.9 \%^{\mathrm{a}}$ & $9.0 \%^{\mathrm{a}}$ & $10.9 \%{ }^{\mathrm{a}}$ & $0.6 \%^{\mathrm{a}}$ & $0.5 \%^{\mathrm{a}}$ & $0.7 \%^{\mathrm{a}}$ \\
\hline \multicolumn{7}{|l|}{ Region of country } \\
\hline South & $3.7 \%^{\mathrm{a}}$ & $7.7 \%{ }^{\mathrm{a}}$ & $7.9 \%^{\mathrm{a}}$ & $0.8 \%^{\mathrm{a}}$ & $0.6 \%^{\mathrm{a}}$ & $0.8 \%^{\mathrm{a}}$ \\
\hline Northeast & $2.9 \%$ & $5.7 \%{ }^{\mathrm{b}}$ & $7.5 \%^{\mathrm{a}}$ & $0.6 \%^{\mathrm{a}}$ & $0.8 \%^{\mathrm{a}}$ & $0.6 \%^{\mathrm{a}}$ \\
\hline Midwest & $2.5 \%^{\mathrm{b}}$ & $7.3 \%{ }^{\mathrm{a}, \mathrm{b}}$ & $9.4 \%^{\mathrm{a}}$ & $0.4 \%^{\mathrm{a}}$ & $0.5 \%^{\mathrm{a}}$ & $0.6 \%^{\mathrm{a}}$ \\
\hline West & $4.6 \%^{\mathrm{a}}$ & $7.5 \%{ }^{\mathrm{a}, \mathrm{b}}$ & $8.1 \%^{\mathrm{a}}$ & $0.6 \%^{\mathrm{a}}$ & $0.8 \%^{\mathrm{a}}$ & $0.5 \%^{\mathrm{a}}$ \\
\hline \multicolumn{7}{|l|}{ Population density } \\
\hline Female & $3.5 \%{ }^{\mathrm{a}}$ & $6.8 \%{ }^{\mathrm{a}}$ & $6.4 \%^{\mathrm{a}}$ & $0.6 \%^{\mathrm{a}}$ & $0.4 \%^{\mathrm{a}}$ & $0.6 \%^{\mathrm{a}}$ \\
\hline Male & $3.5 \%^{\mathrm{a}}$ & $7.6 \%^{\mathrm{a}}$ & $10.3 \%^{\mathrm{b}}$ & $0.6 \%^{\mathrm{a}}$ & $1.0 \%{ }^{\mathrm{b}}$ & $0.7 \%^{\mathrm{a}}$ \\
\hline \multicolumn{7}{|l|}{ Race/ethnicity } \\
\hline White & $2.8 \%^{\mathrm{a}}$ & $7.5 \%{ }^{\mathrm{a}}$ & $8.8 \%^{\mathrm{a}}$ & $0.5 \%^{\mathrm{a}}$ & $0.7 \%^{\mathrm{a}}$ & $0.6 \%^{\mathrm{a}}$ \\
\hline Black & $2.0 \%^{\mathrm{a}}$ & $3.9 \% \mathrm{~b}$ & $5.9 \%^{\mathrm{b}}$ & $0.9 \%^{\mathrm{a}}$ & $0.9 \%^{\mathrm{a}}$ & $1.2 \%^{\mathrm{b}}$ \\
\hline Hispanic & $5.9 \%^{\mathrm{b}}$ & $7.2 \%{ }^{\mathrm{a}}$ & $8.6 \%$ & $0.9 \%^{\mathrm{a}}$ & $0.5 \%{ }^{\mathrm{a}}$ & $0.8 \%^{\mathrm{a}, \mathrm{b}}$ \\
\hline Other races & $4.4 \%{ }^{\mathrm{b}}$ & $7.9 \%^{\mathrm{a}}$ & $7.2 \%{ }^{\mathrm{a}, \mathrm{b}}$ & $0.7 \%^{\mathrm{a}}$ & $0.6 \%^{\mathrm{a}}$ & $0.6 \%$ a,b \\
\hline \multicolumn{7}{|l|}{ Parent education } \\
\hline High school or less & $5.2 \%{ }^{\mathrm{a}}$ & $9.9 \%{ }^{\mathrm{a}}$ & $9.1 \%^{\mathrm{a}}$ & $1.0 \%{ }^{\mathrm{a}}$ & $0.9 \%^{\mathrm{a}}$ & $0.9 \%^{\mathrm{a}}$ \\
\hline Some college or more & $3.0 \%{ }^{b}$ & $6.3 \%^{\mathrm{b}}$ & $8.0 \%^{\mathrm{a}}$ & $0.5 \% \mathrm{~b}$ & $0.6 \%^{\mathrm{a}}$ & $0.6 \%^{\mathrm{a}}$ \\
\hline \multicolumn{7}{|l|}{ Family composition } \\
\hline None or one parent & $5.0 \%{ }^{\mathrm{a}}$ & $10.5 \%{ }^{\mathrm{a}}$ & $10.6 \%{ }^{\mathrm{a}}$ & $1.1 \%^{\mathrm{a}}$ & $1.1 \%{ }^{\mathrm{a}}$ & $1.0 \%{ }^{\mathrm{a}}$ \\
\hline
\end{tabular}

Notes. Weighted sample sizes for 8th/10th/12th grades: 'synthetic marijuana' Ns=9665/10655/10057; 'bath salts' Ns=9640/10655/ 10068. ${ }^{\mathrm{a}, \mathrm{b}, \mathrm{c}}$ Superscript letters are shorthand to indicate pairwise comparisons within grade and subgroup for each drug. Similarities are noted first. The same superscript letters within grade and subgroup for each drug indicate that values do not differ significantly from the others within that grade and subgroup. If values do not share the same superscript letter, these different superscript letters indicate significant differences at $P<0.05$ among the values within grade and subgroup for each drug. For example, use of 'synthetic marijuana' for 8 th graders by region of country shows that South, Northeast and West do not differ significantly (marked ${ }^{\mathrm{a}}$ ), nor do Northeast and Midwest (marked ${ }^{\mathrm{b}}$ ); however, South and Midwest differ significantly from each other, as do Midwest and West.

marijuana use in the past 12 months for 12 th graders were associated with use of 'synthetic marijuana.'

\section{Discussion}

Despite dangers associated with use of synthetic cannabinoids and synthetic cathinones, very little information regarding the prevalence rates or characteristics of adolescent users is available. This is among the first studies to document the national prevalence of synthetic drugs as a function of historical year, sociodemographic characteristics and other adolescent behaviors. The present study further elaborates on recent work examining correlates of use of synthetic cannabinoids [11] and synthetic cathinones [22] among 12th graders by including 8th and 10th graders and more recent data. This information is designed to help identify and target youth at risk for novel psychoactive substance use. Although synthetic cannabinoid use has decreased in the past 2 years, the drug remains relatively prevalent [2]. Prevalence of synthetic cathinones use is not high, but identifying the adolescents at greatest risk remains important considering the severity of potential consequences and the emergence of problems associated with newly emerging variations of the drugs.

Similar to previous research on use and consequences $[2,11,23]$, we found limited support for gender differences with boys reporting more synthetic cannabinoids use in 12 th grade (used by $10.3 \%$ of boys and $6.4 \%$ of 


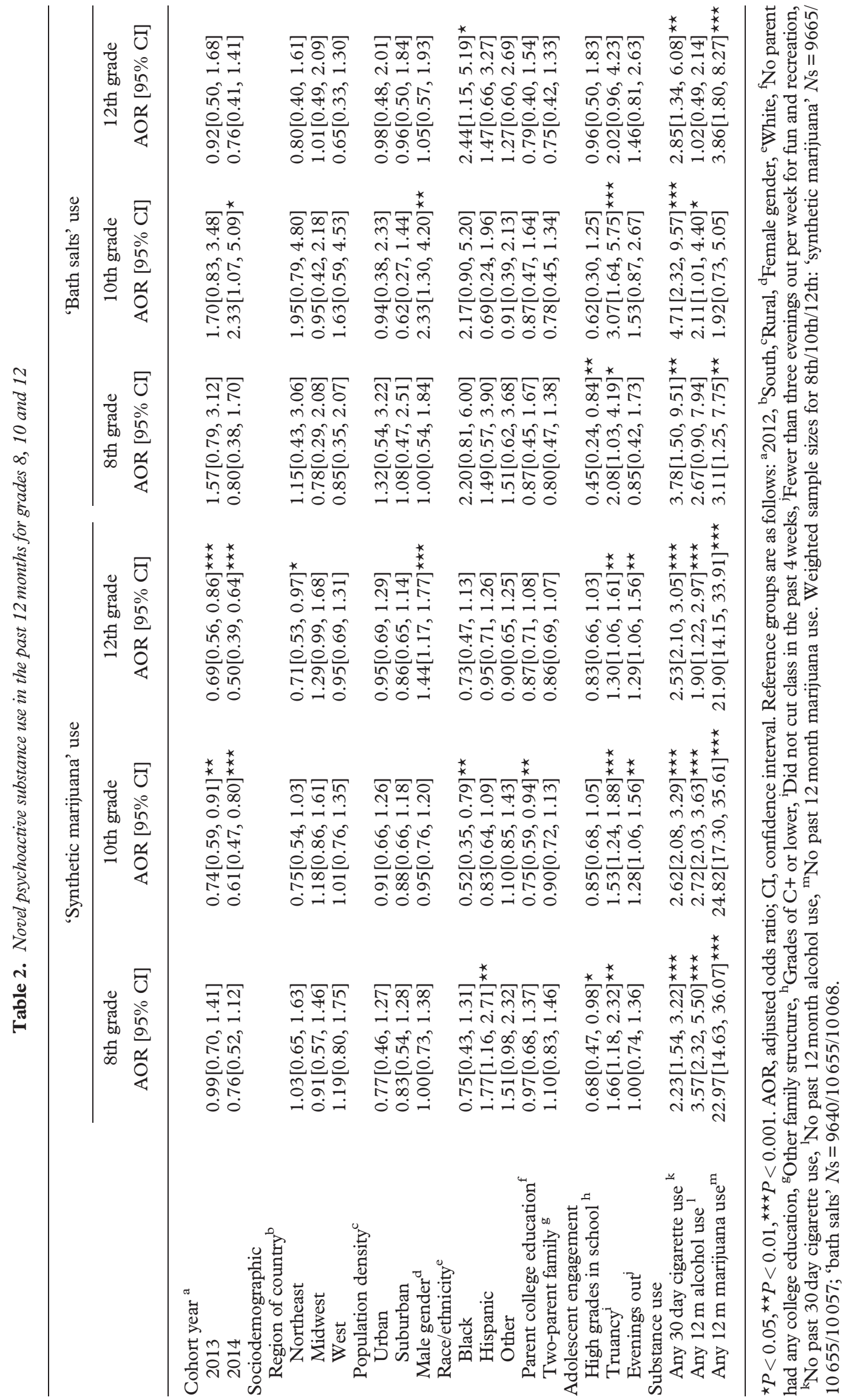


girls) and synthetic cathinones use in 10 th grade (used by $1.0 \%$ of boys and $0.4 \%$ of girls).

Based on multivariable models including other substance use, relatively few differences in prevalence were observed for sociodemographics including region, population density, gender, race/ethnicity and parental education. Higher grades in school were associated with less synthetic substance use, but only for eighth graders, suggesting that early signs of low grades may be a specific indicator of risk. Truancy was associated with use of synthetic drugs. Evenings out for fun and recreation was also associated with synthetic cannabinoid use, but only among high school students (10th and 12th graders). Use of cigarettes, alcohol and marijuana was the most consistently associated with synthetic drug use, suggesting that existing screens for substance use may identify adolescents who use or are at risk for using synthetic drugs. These findings are consistent with existing research documenting that other substance use is the most robust predictor of synthetic drug use [11].

Limitations of the study include that the data are crosssectional, self-reported and based on in-school surveys, so school dropouts are not included. Nonetheless, this study points prevention and intervention efforts toward polysubstance using US adolescents and those who are disengaged from school. Future research should continue to track the historical changes in the use of these drugs and their associated consequences, as well as assess the reasons adolescents report for using novel psychoactive substances and how these may or may not correspond to reasons for using other substances.

\section{Acknowledgements}

Data collection and work on this study were funded by the support from the National Institute on Drug Abuse (R01 DA 001411). The content here is solely the responsibility of the authors and does not necessarily represent the official views of the sponsors.

\section{References}

[1] Lindsay L, White ML. Herbal marijuana alternatives and bath salts-'barely legal' toxic highs. Clin Pediatr Emerg Med 2012;13:283-91.

[2] Johnson LA, Johnson RL, Portier RB. Current 'legal highs'. J Emerg Med 2013;44:1108-15.

[3] Volkow N. Dangerous Synthetic Drugs. Presented to the Caucus on International Narcotics Control, United States Senate. National Institute on Drug Abuse, 2013. Available from: http://www.drugabuse.gov/about-nida/ legislative-activities/testimony-to-congress/2013/dangerous-synthetic-drugs. Accessed: 1 August 2015.

[4] American Association of Poison Control Centers. American Association of Poison Control Centers Issues Warning About Reemerging Synthetic Drugs. 2015. Available from: http://www.aapcc.org/press/43/. Accessed: 1 May 2015.

[5] Cohen JA. The highs of tomorrow: why new laws and policies are needed to meet the unique challenges of synthetic drugs. J L \& Health 2014;27:1-23.

[6] United States Drug Enforcement Administration. Drugs of Abuse Resource Guide. 2011. Available from: http://www.dea.gov/docs/ drugs_of_abuse_2011.pdf. Accessed: 1 February 2015.

[7] National Institute on Drug Abuse. Nida for Teens-the Science of Drug Facts: What is Spice? National Institute on Drug Abuse, 2015. Available from: http://teens.drugabuse.gov/drug-facts/spice. Accessed: 1 February 2015.

[8] National Institute on Drug Abuse. Nida for Teens - the Science of Drug Facts: What are Bath Salts? National Institute on Drug Abuse, 2015. Available from: http://teens.drugabuse.gov/drug-facts/bath-salts. Accessed: 1 February 2015.

[9] Winstock A, Lynskey M, Borschmann R, Waldron J. Risk of emergency medical treatment following consumption of cannabis or synthetic cannabinoids in a large global sample. J Psychopharmacol 2015;29:698-703.

[10] Miech RA, Johnston L, O'Malley PM, Bachman JG, Schulenberg JE. Monitoring the Future National Survey Results on Drug use, 1975-2014: Volume I, Secondary School Students. Ann Arbor, MI: Institute for Social Research, The University of Michigan, 2015. Available from: http:// monitoringthefuture.org/pubs/monographs/mtf-vol1_2014.pdf.

[11] Palamar JJ, Acosta P. Synthetic cannabinoid use in a nationally representative sample of us high school seniors. Drug Alcohol Depend 2015;149:194-202.

[12] Seely KA, Lapoint J, Moran JH, Fattore L. Spice drugs are more than harmless herbal blends: a review of the pharmacology and toxicology of synthetic cannabinoids. Prog Neuropsychopharmacol Bol Psychiatry 2012;39:234-43.

[13] Hermanns-Clausen M, Kneisel S, Szabo B, Auwarter V. Acute toxicity due to the confirmed consumption of synthetic cannabinoids: clinical and laboratory findings. Addiction 2013;108:534-44.

[14] Besli GE, Ikiz MA, Yildirim S, Saltik S. Synthetic cannabinoid abuse in adolescents: a case series. J Emerg Med 2015;49:644-50.

[15] Pierre JM. Cannabis, synthetic cannabinoids, and psychosis risk: what the evidence says. Current Psychiatry 2011;10:49-57.

[16] Winstock AR, Barratt MJ. The 12-month prevalence and nature of adverse experiences resulting in emergency medical presentations associated with the use of synthetic cannabinoid products. Hum Psychopharmacol 2013;28:390-3.

[17] Miotto K, Striebel J, Cho AK, Wang C. Clinical and pharmacological aspects of bath salt use: a review of the literature and case reports. Drug Alcohol Depend 2013;132:1-12.

[18] Baumann $\mathrm{MH}$. Awash in a sea of 'bath salts': implications for biomedical research and public health. Addiction 2014;109:1577-9.

[19] Substance Abuse and Mental Health Services Administration, Drug abuse Warning Network. 'Bath Salts' Were Involved in Over 20000 Drugrelated Emergency Department Visits in 2011. Rockville, MD: Substance Abuse and Mental Health Services Administration, 2013. Available from: http://www.samhsa.gov/data/sites/default/files/spot117-bath-salts-2013/ spot117-bath-salts-2013.pdf Accessed: 1 August 2015.

[20] Bachman JG, Johnston LD, O'Malley PM, Schulenberg JE, Miech RA. The Monitoring the Future Project After Four Decades: Design and Procedures (Monitoring the Future Occasional Paper no. 82). Ann Arbor, MI: Institute for Social Research, 2015. Available from: http://monitoringthefuture.org/ pubs/occpapers/mtf-occ82.pdf.

[21] SAS Institute Inc. Sas/Stat Software: Version 9.4. Cary, NC: SAS Institute Inc., 2012.

[22] Palamar JJ. 'Bath salt' use among a nationally representative sample of high school seniors in the united states. Am J Addict 2015;24:488-91.

[23] Barratt MJ, Cakic V, Lenton S. Patterns of synthetic cannabinoid use in Australia. Drug Alcohol Rev 2013;32:141-6. 